\title{
A percepção de educandos em relação às ações do PNAE voltadas ao desenvolvimento sustentável
}

O presente artigo tem o objetivo de verificar a percepção dos educandos de uma escola pública de grande porte em relação às ações do Programa Nacional de Alimentação Escolar (PNAE). A pesquisa é de cunho exploratório e quantitativo, do tipo survey, feita a partir da análise de educandos de uma escola pública do estado do Paraná, tendo como referência a merenda escolar preparada com alimentos orgânicos. No desenvolvimento da pesquisa, utilizou-se o modelo Vapercom, desenvolvido por Brandalise (2008), cuja proposta é a de identificar o grau de percepção da variável ambiental na cadeia produtiva, na ótica da redução, na reutilização e na reciclabilidade dos recursos, associado ao comportamento do consumidor, considerando a Análise do Ciclo de Vida do produto (ACV). A coleta de dados foi realizada por meio de um questionário com 42 questões objetivas e a amostra foi de 999 alunos pesquisados do referido colégio. Para a tabulação e análise dos dados coletados, dispôs-se de planilhas de Excel. A partir dos resultados obtidos em meio ao presente trabalho, pôde-se observar que a maioria dos estudantes não sabe que a própria escola a que frequentam prepara a merenda com base fundamentalmente em produtos orgânicos e livres de agrotóxicos. A partir dos resultados apresentados nesse trabalho, está evidenciado que a escola precisa melhorar suas ações referentes à informação dos alunos sobre os alimentos orgânicos utilizados no preparo da merenda escolar e, também, às ações relativas ao desenvolvimento sustentável.

Palavras-chave: Orgânicos; Educação Ambiental; ACV; Consciência Ambiental; Saúde.

\section{The students's perception regarding to the PNAE's actions aimed at the sustainable development}

\begin{abstract}
This article aims to verify the perception of students from a large public school in relation to the actions of the National School Feeding Program (PNAE). The research nature is exploratory and quantitative, from the "survey" type, realized from the students analysis of a public school in the state of Paraná, with reference to the school meal prepared with organic foods. In the research, it was used the Vapercom model, developed by Brandalise (2008), whose purpose is to identify the degree of perception of the environmental variable in the production chain, from the perspective of reduction, reuse and recyclability of resources, associated to the consumer behavior, considering the Analysis of the Product's Life Cycle (ACV). The data collection was conducted through a questionnaire with 42 objective questions and the sample was 999 students researched of that school. For tabulation and analysis of the data collected, $i$ was used Excel spreadsheets. From the results obtained in this study, it was observed that most students do not know that the school they attend prepares meals based mainly on organic products and pesticide-free. From the results presented in this work, it is evidenced that the school needs to improve its actions regarding to the information of students about organic foods used in the preparation of school meals and, also, to actions relating to sustainable development.
\end{abstract}

Keywords: Organic; Environmental Education; ACV; Environmental Awareness; Health.

Topic: Consumo e Meio Ambiente

Reviewed anonymously in the process of blind peer

Solange Maria Debastiani

Universidade Estadual do Oeste do Paranà

http://lattes.cnpq.br/8342818757587670

sdebastiani@hotmail.com

Jamila El Tugoz

Universidade Estadual do Oeste do Paraná http://lattes.cnpq.br/1284885326431045 jamila_eltugoz@hotmail.com

\section{Loreni Teresinha Brandalise}

Universidade Estadual do Oeste do Paraná

http://lattes.cnpq.br/1911512871041432

lorenibrandalise@gmail.com

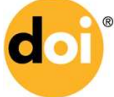

DOI: 10.6008/SPC2179-6858.2016.001.0001
Received: 01/06/2015

Approved: 16/11/2015
Referencing this:

DEBASTIANI, S. M.; TUGOZ, J. E.; BRANDALISE, L. T.. A percepção de educandos em relação às ações do PNAE voltadas ao desenvolvimento sustentável. Revista Ibero-Americana de Ciências Ambientais, v.7, n.1, p.06-28, 2016. DOI: http://doi.org/10.6008/SPC21796858.2016.001.0001 


\section{INTRODUÇÃO}

O atual modelo de crescimento econômico baseado na maximização da produção e do consumo tem gerado enormes desequilíbrios tanto de ordens econômica e social quanto ambiental. Em função dos impactos ambientais verificados nas últimas décadas, a necessidade de uma transição para um futuro ambientalmente amigável se torna mais evidente a cada dia (RASMUSSEN, 2011).

Um novo paradigma de desenvolvimento centrado na sustentabilidade vem concedendo novas perspectivas de ampliação desse campo de pesquisa no século 21 (SACHS, 2004; JACOBI, 2003). Para Rohrich e Cunha (2004), historicamente, países como o Brasil, em virtude do atraso em aspectos tecnológicos, educacionais e sociais, priorizaram o progresso econômico sem buscar conciliá-lo ao meio ambiente. Todavia, entende-se que, nos últimos anos, houve crescimento no Brasil da gestão socioambiental, que envolve a combinação de boas práticas administrativas à preservação da natureza, ampliando os compromissos da empresa com as necessidades e as expectativas de seus stakeholders e com o ecossistema, complementa Ferreira (2012).

O consumo sustentável surge como alternativa, visto que seus princípios envolvem não apenas o incentivo ao consumo, como também uma preocupação com os aspectos da coletividade, à luz do desenvolvimento sustentável. Faz-se necessário, então, o desenvolvimento de uma conscientização coletiva, de uma atuação mais ativa das instituições governamentais, bem como de uma prática proativa por parte das organizações. A superveniência dessa necessidade se dá, sobretudo no que tange à busca por alternativas na prestação de produtos e serviços, visando a atuar em conjunto com essa faixa da população, e sem esquecer, contudo, da redução dos impactos possivelmente causados (SILVA; BALBINO; GÓMEZ, 2011).

De acordo com Krischke e Tomiello (2009), os orgânicos refletem uma nova consciência que tem sido analisada pelos consumidores, abrangendo questões múltiplas, a exemplo da preocupação com a ecologia e do bem-estar individual. Cahill, Morley e Powell (2010) confirmam que, historicamente, "meio ambiente" e "saúde" vêm sendo os construtos mais associados aos alimentos orgânicos. As pessoas estariam, portanto, cada vez mais interessadas em consumir esses alimentos, guiadas por consciência ambiental, por preocupação com a saúde e, mesmo, por questões de ordem moral e social (OZCELIK; UÇAR, 2008; GIL; GRACIA; SANCHEZ, 2000).

Brandalise et al. (2009) destacam que as ações do homem influenciarão no futuro da natureza e do planeta. Assim, infere-se que, a partir do conhecimento e da percepção ambiental, as atitudes e o comportamento humano poderão ser modificados. A Análise do Ciclo de Vida do Produto (ACV) pode ser utilizada para se obter um entendimento mais coeso de todo o sistema de produção de um produto para que assim, consequentemente, se consiga aprimorá-lo. Para isso, novos hábitos de consumo pressionariam as organizações a produzirem produtos ecologicamente corretos rumo ao desenvolvimento sustentável.

Ainda em relação aos orgânicos, o Programa Nacional de Alimentação Escolar (PNAE), instituído pela Lei no 11.947/2009, prevê, dentre suas ações, a obrigatoriedade de que, no mínimo, 30\% dos gêneros alimentícios fornecidos nas escolas públicas advenham da agricultura familiar, priorizando-se os produtos 
orgânicos. Nesse sentido, a questão que norteia esse estudo é: os educandos de uma escola pública de grande porte percebem a importância das ações do PNAE para o desenvolvimento sustentável?

Tendo-se elaborado a pergunta de pesquisa, procede-se à verificação do propósito central desse artigo, que é o de pesquisar a percepção dos educandos de uma escola pública de grande porte em relação às ações do PNAE voltadas ao desenvolvimento sustentável. Para atingir a meta proposta, tem-se como objetivo específico a verificação da percepção e do comportamento dos educandos em relação às questões ambientais, considerando a ACV.

Destaca-se, outrossim, que o presente trabalho está estruturado em cinco partes: a primeira apresenta a introdução do estudo, a segunda aborda a fundamentação teórica utilizada para a realização do trabalho, a terceira descreve os procedimentos metodológicos, a quarta apresenta os resultados e discussões obtidos segundo adaptação do modelo VAPERCOM e, finalmente, a quinta traz as considerações finais.

\section{REVISÃO TEÓRICA}

\section{Desenvolvimento Sustentável}

A expressão "desenvolvimento sustentável" se tornou popular após a Conferência das Nações Unidas sobre o Meio Ambiente e Desenvolvimento, realizada no Rio de Janeiro, em 1992, embora já estivesse presente, com diferentes denominações, desde a Conferência de Estocolmo, em 1972 (BARBIERI; SILVA, 2011)

A definição de desenvolvimento sustentável encontrada no Relatório de Brundtland é descrita como

sendo: "[...] um processo de mudança em que a exploração dos recursos, a direção dos investimentos, a orientação do desenvolvimento tecnológico e a mudança institucional estão em harmonia" para que as necessidades humanas possam ser satisfeitas atualmente e no futuro (WCED, 1987). Com o mesmo direcionamento, o conceito de desenvolvimento sustentável do Ministério do Meio Ambiente (MMA) (2007), abrange a prática e o consumo que utilizam os recursos naturais para a satisfação das necessidades atuais, sem comprometer, contudo, as necessidades e aspirações das gerações futuras.

Paulista, Varvakis e Montibeller-Filho (2008) defendem que não há consenso a respeito da definição de desenvolvimento sustentável e que a proposição mais aceita congrega um equilíbrio entre as possibilidades de crescimento e as ponderações de bem-estar da sociedade. De forma complementar, Pearce (1988) ressalta que o desenvolvimento sustentável envolve um padrão de mudanças econômicas, estruturais e sociais. Ou seja, otimiza a utilização dos recursos econômicos e dos aspectos sociais, além de preservar os benefícios similares para o futuro.

De acordo com Bonilla, Almeida, Giannetti e Huisingh (2010), para a maior inserção da variável ambiental nas estratégias empresariais e, consequentemente, para a transição com vistas a uma sociedade mais sustentável, há que se atentar à adoção de algumas ações consideradas ambientalmente saudáveis. A exemplo dessas atividades almejadas, tem-se o uso mais eficiente e consciente de matérias-primas e de 
energias não-renováveis e renováveis; e implementação mais ampla de sistemas de gerenciamento do ciclo de vida do produto.

Entendendo que, de forma alguma, o consumo pode deixar de ser praticado pela população, destacase o viés coletivo dessa prática, considerado consciente e que se efetiva ao se levar em consideração os impactos provocados pelo consumo, buscando maximizar os positivos e minimizar os negativos, de acordo com os princípios da sustentabilidade. Desse modo, torna-se possível perceber que há a possibilidade de redirecionamento das características de consumo, considerando a nova ideia emergente de preocupação com a busca do desenvolvimento sustentável (INSTITUTO AKATU, 2010).

Assim, o Estado, pelas atribuições que the são conferidas, pode direcionar seus esforços em diferentes vertentes para auxiliar o alcance eficaz do desenvolvimento sustentável. Nesse aspecto, é possível afirmar que o papel do governo é o de regular e de fiscalizar as atividades gerais que, por algum motivo, encontrem-se desviadas desse objetivo, bem como o de financiar e de fomentar o surgimento de alternativas capazes de sustentar ações humanas sobre o meio ambiente, visando a melhor organizar a sociedade. Tal aspecto envolve maior empenho público, sendo que os governantes do país devem ter a percepção de que suas ações podem interferir diretamente nas práticas sociais a curto, médio e longo prazo (SILVA; BALBINO; GÓMEZ, 2011).

Ao final da Conferência de Estocolmo na Suécia, conforme Dias (1994), confiou-se à educação ambiental a tarefa de mudar os hábitos necessários para um relacionamento mais adequado frente ao meio ambiente. Assim, se atribuiu a à disciplina de educação ambiental a tarefa de desenvolver a consciência ambiental e de fomentar as condutas que levassem as pessoas a se envolverem de fato com as questões ambientais.

A Lei no 9.795 de 1999 incumbe, entre outros órgãos, as instituições educativas de promoverem a educação ambiental, devendo, para tanto, integrar os temas afins à questão ao desenvolvimento de seus programas educacionais. Os objetivos fundamentais da educação ambiental citadas no artigo 5o são:

\footnotetext{
I - $O$ desenvolvimento de uma compreensão integrada do meio ambiente em suas múltiplas e complexas relações, envolvendo aspectos ecológicos, psicológicos, legais, políticos, sociais, econômicos, científicos, culturais e éticos; II - A garantia de democratização das informações ambientais;

III - o estímulo e o fortalecimento de uma consciência crítica sobre a problemática ambiental e social;

IV - O incentivo à participação individual e coletiva, permanente e responsável, na preservação do equilíbrio do meio ambiente, entendendo-se a defesa da qualidade ambiental como um valor inseparável do exercício da cidadania;

$\checkmark$ - O estímulo à cooperação entre as diversas regiões do País, em níveis micro e macrorregionais, com vistas à construção de uma sociedade ambientalmente equilibrada, fundada nos princípios da liberdade, igualdade, solidariedade, democracia, justiça social, responsabilidade e sustentabilidade;

$\mathrm{VI}$ - o fomento e o fortalecimento da integração com a ciência e a tecnologia;

VII - o fortalecimento da cidadania, autodeterminação dos povos e solidariedade como fundamentos para o futuro da humanidade.
}

A Lei no 9.795 de 1999, que institui a Política Nacional de Educação Ambiental objetiva a promoção da educação ambiental e que inclui todos os atores da sociedade, porém, com uma característica que se 
diferencia das demais disposições legais existentes até então, que não estabelece regras e sanções, mas sim responsabilidades e obrigações. Sendo assim, essa lei institucionaliza a Educação Ambiental, transformandoa em política pública. Nesse contexto, os temas ambientais devem fazer parte dos currículos escolares de forma interdisciplinar, multidisciplinar e transdisciplinar (CUNHA, 2010).

Nessa direção, Kopeginski e Sakamoto (2010, p.246) concordam que a Educação Ambiental busca, "por meio de conteúdos de cunho ambiental, instrumentalizar o educando para que ele aja de maneira consciente" no meio em que está inserido. Além disso, "É imprescindível que a escola cumpra com o seu papel de formar cidadãos críticos capazes de se inserirem na sociedade [...], oferecendo ao aluno conhecimentos que lhe possibilitem agir eticamente sobre o ambiente natural" complementam os mesmos autores.

\section{Percepção, Comportamento e Educação Ambiental}

Slater (2002, p.17) cita que "[...] o consumo é sempre em todo lugar um processo cultural". Desse modo, segundo o autor, a cultura de consumo vai além da reprodução da vida cotidiana, atingindo, de modo dominante, um alcance prático e uma profundidade ideológica que permitem estruturar e subordinar as outras culturas. A sociedade e o consumo a que a população está submetida na atualidade demonstram o quão cultural é a prática de consumir e, além disso, o quanto esta demanda envolvimento das relações interpessoais.

Para Elkington, Hailes e Makower (1990), pessoas conscientes de suas ações individuais, bem informadas e preocupadas com questões ambientais surgiriam como uma nova estratégia para a solução dos problemas ligados ao consumo e, também, como início de mudanças em direção à sociedade sustentável.

Complementando a visão dos autores, para Bertolini et al. (2013), quando os consumidores possuem uma completa consciência ambiental, são considerados consumidores ecológicos, os quais atribuem um alto valor aos produtos ecologicamente corretos. Verifica-se, ainda, que estão dispostos a pagar mais por produtos que não agridam o meio ambiente, que esperam das organizações ações ambientais proativas, certificações ambientais, produtos e embalagens fabricados com materiais reciclados e reaproveitáveis, além de produtos biodegradáveis, orgânicos e que consumam menos energia ou água, ou seja, que, em geral, demandam grandes investimentos financeiros.

Ainda, segundo Bertolini et al. (2013), em contrapartida, há consumidores que possuem pouco interesse quanto à harmonia do meio ambiente, tendo nível de consciência ambiental baixo, bem como o valor que atribuem aos produtos ecológicos. Para este público, a possibilidade de compra de produtos ecológicos acontece basicamente se os preços estiverem menores do que os apresentados pelos concorrentes. Com base nessa condição, é possível que eles comprem produtos de material reciclado, orgânico, reaproveitáveis e que demandem baixos investimentos financeiros das empresas fabricantes.

Dessa forma, a pesquisa em percepção ambiental é um importante elemento para o planejamento do ambiente, já que uma das dificuldades para a proteção dos ambientes naturais está na existência das 
diferenças de percepções dos valores, da importância atribuída a eles por indivíduos de culturas diferentes ou de grupos socioeconômicos que desempenham funções distintas no plano social, nesses ambientes naturais (UNESCO 1997).

Uma das soluções apontadas é a transformação do modo de consumir, adotando um comportamento que permita que os cidadãos tomem as decisões acertadas em seus atos de consumo, adquirindo consciência do impacto coletivo, ambiental e social em que se traduzem suas opções individuais de consumo para a promoção da qualidade de vida e do desenvolvimento local (COSTA; TEODÓSIO, 2011).

Como as práticas de consumo são individuais, percebe-se que cada sujeito possui a faculdade de escolha sobre suas ações, que há de ser feita, cada vez mais, seguindo a ideia de mudança de paradigma e considerando-a viável. Santos et al. (2008) afirmam que estão surgindo novas preocupações por parte do consumidor, que mudou o foco individualista de seu consumo para uma visão mais ampla, dando origem a novos comportamentos, que visa a um consumo mais consciente.

Para Brandalise et al. (2009), as escolas podem ser um instrumento de divulgação da educação ambiental. A matéria, por sua vez, deve estar comprometida com uma abordagem da problemática ambiental que inter-relacione os aspectos sociais, ecológicos, econômicos, políticos, culturais, científicos, tecnológicos e éticos. Dessa maneira, há que se considerar o nível de complexidade de se compreender com clareza os limites e as possibilidades da educação ambiental. Por esse motivo, a autora recomenda o desenvolvimento de projetos simples e objetivos, ajustados à vivência do cotidiano casa/escola/comunidade, por meio da interdisciplinaridade.

Serrano (2003) infere que, embora planejem fazê-lo, as escolas não estão conseguindo concretizar as expectativas a fim de propiciar uma mudança de valores e atitudes, adequando-os ao consumismo ambiental. Os alunos, em geral, não se comprometem com os objetivos comportamentais da educação ambiental, o que resulta em um consumo de produtos ambientalmente incorretos, comprovando a existência de um descompasso entre teoria e prática.

Por essa razão, é necessário conhecer como o estudante se posiciona enquanto consumidor diante dos diferentes discursos e o que leva em consideração ao escolher determinado produto ou marca (BRANDALISE et al., 2009).

Assim, Brandalise (2008), sugere o uso de ferramentas de educação ambiental nas políticas públicas para orientar as escolas brasileiras, convergindo na qualidade do processo de desenvolvimento na perspectiva do desenvolvimento sustentável, razão pela qual uma série de sistemas de indicadores vem sendo construída buscando mensurar o grau de sustentabilidade. Os fatores de pesquisa em voga são os de desenvolvimento sustentável apontando para as variáveis ambientais, sociais e econômicas.

\section{Produtos Orgânicos}

A expressão "alimento orgânico" foi utilizada pela primeira vez na década de 1940, embora o conceito subjacente seja muito mais antigo (JONES et al. 2001). Conforme exposto na Lei no 10.831 de 23 de 
dezembro de 2003, que dispõe sobre a agricultura orgânica no Brasil, "produto orgânico" é todo produto obtido, seja ele processado ou in natura, em sistema orgânico de produção agropecuário ou oriundo de processo extrativista sustentável e não prejudicial ao ecossistema local (BRASIL, 2003).

São características dos sistemas orgânicos de produção: a oferta de produtos isentos de contaminantes intencionais; a preservação da diversidade biológica dos ecossistemas naturais e a recomposição ou incremento da diversidade biológica dos ecossistemas modificados em que se insere o sistema de produção; o incentivo à integração entre os diferentes segmentos da cadeia produtiva e de consumo de produtos orgânicos; e a regionalização da produção e comércio desses produtos (BRASIL, 2007).

Assim, os alimentos oriundos da agricultura orgânica são definidos pelas práticas e pelos insumos utilizados em seus processos produtivos e não por propriedades intrínsecas aos produtos dessa prática resultantes (ZAKOWSKA-BIEMANS, 2011; SAHER; LINDERMAN; ULLA-KAISA, 2006).

Por serem provenientes de sistemas de produção agrícola que, conceitualmente, visam a manejar de forma equilibrada o solo e os demais recursos naturais - como água, vegetais, animais, macro e microorganismos -, sem o uso de agrotóxicos (TERRAZZAN; VALARINI, 2009), os alimentos orgânicos são considerados mais saudáveis do que os alimentos convencionais (RADMAN, 2005).

Ainda não existem testes científicos que atestem se um alimento é ou não cultivado organicamente (POULSTON; YAU; YIU, 2011) e também não se pode visualizar a diferenciação no próprio produto, visto que a diferença ocorre durante o processo produtivo (RODRIGUES et al., 2010). Por este motivo, os controles se concentram na maneira pela qual eles são produzidos.

Assim, para que um alimento seja considerado orgânico, deve receber um selo de certificação que identifica a procedência do produto e, além disso, atesta que as práticas de cultivo são livres de fertilizantes químicos ou de agrotóxicos (TERRAZZAN; VALARINI, 2009; DENOBILE, 2005; COLTRO, 2006; POULSTON; YAU; YIU, 2011).

A certificação, além de garantir ao consumidor a aquisição de um produto original, protegendo-o de possíveis fraudes, também permite aos agricultores diferenciarem seus produtos daqueles cultivados de forma convencional (TERRAZZAN; VALARINI, 2009).

Santos et al. (2012) afirma que a integração de políticas e de programas atuará para potencializar e valorizar a produção orgânica, a partir da participação de vários setores, a exemplo do da saúde, da educação e da agricultura. Não obstante a isso, essa relação a ser estabelecida, segundo o autor (2012), também tende a corroborar para uma maior e mais abrangente inserção de alimentos orgânicos na alimentação escolar.

\section{Programa Nacional de Alimentação Escolar (PNAE)}

Para Soares e Vicente (2011), a alimentação escolar é importante fator contributivo no que tange à contribuição para o crescimento, o desenvolvimento, a aprendizagem e o rendimento escolar dos estudantes. Neste sentido, em 1955 foi implantado o Programa Nacional de Alimentação Escolar - PNAE, com o intuito de atender às necessidades nutricionais dos alunos e também com o objetivo de promover a 
formação de hábitos saudáveis de alimentação.

Em um primeiro momento, o PNAE abrangia o fornecimento de alimentação escolar para alunos da educação infantil e do ensino fundamental matriculados em escolas públicas e filantrópicas. A partir de 2009, contudo, por meio da Medida Provisória no 455/2009 (convertida, posteriormente, na Lei no 11.947/2009), foi assegurado o direito à alimentação escolar também a todos os alunos do ensino médio e da educação para jovens e adultos (EJA).

A Lei no 11.947/2009 dispõe sobre o atendimento da alimentação escolar e consolida a vinculação da agricultura familiar ao PNAE, ao estipular que, no mínimo, 30\% dos recursos financeiros repassados pelo Governo Federal aos estados e municípios para a aquisição dos gêneros alimentícios fornecidos nas escolas públicas devem advir da agricultura familiar, priorizando-se os alimentos orgânicos, consoante o que destacam Soares e Vicente (2011).

Tal determinação tem o objetivo de apoiar a agricultura familiar e de fortalecer o Programa de Aquisição de Alimentos (PAA), instituído em 2003, pelo artigo 19 da Lei no 10.696/2003. Essa medida prima pela aquisição de produtos, diretamente dos agricultores familiares a um preço considerado justo, sendo as compras realizadas por meio de recursos do Fundo Nacional de Desenvolvimento Escolar (FNDE), sem intermediários e dispensando o processo licitatório (BRASIL, 2003).

Neste cenário, a Secretaria de Estado da Educação do Paraná (SEED, 2013), desempenha papel importante para o desenvolvimento desse âmbito do setor rural, oportunizando a comercialização de forma segura e rentável de oitenta e quatro tipos de alimentos produzidos por agricultores familiares. Dando subsídio material - por meio da aquisição do essencial para que o feitio da merenda -, essa organização se encontra presente na alimentação de escolas estaduais de trezentos e noventa e nove municípios do Estado do Paraná, e é colocada em prática pelo Programa Nacional de Alimentação Escolar (PNAE).

Porém, para participar do referido programa, exige-se que os fornecedores sejam, obrigatoriamente, agricultores familiares, organizados e constituídos em grupos formais de cooperativas ou de associações, além do fato de que devem ser detentores de declaração de aptidão ao Programa Nacional de Fortalecimento da Agricultura Familiar - DAP Jurídica, conforme postula a Lei Federal no 11.326, de 24 de julho de 2006, e enquadrados no Programa Nacional de Fortalecimento da Agricultura Familiar (PRONAF).

O Programa Nacional de Alimentação Escolar (PNAE) atinge destaque em meio aos demais programas sociais existentes no país não apenas pelo tempo de existência, mas também pela dimensão do atendimento prestado. É considerado, outrossim, uma estratégia de promoção da Segurança Alimentar e Nutricional, por garantir a oferta de alimentação nos intervalos das atividades escolares a todos os alunos de escolas públicas e filantrópicas do País (GOMES; CAMPOS; MONEGO, 2012).

\section{Modelo Vapercom}

A proposta do modelo Vapercom de Brandalise (2008) é a de identificar o grau de percepção da variável ambiental na cadeia produtiva, na ótica da redução, na reutilização e na reciclabilidade dos recursos, 
associada ao comportamento do consumidor. O modelo proposto pela autora relaciona a variável ambiental, a percepção e o comportamento do consumidor com base na existência de um processo que orienta a conduta do consumidor, influenciada por variáveis ambientais que são consideradas no seu consumo, de acordo com sua percepção (BRANDALISE et al., 2009).

O modelo Vapercom é composto de quatro etapas, sendo que a primeira etapa realiza a caracterização do produto e do potencial consumidor; a segunda etapa destina-se à Identificação de perfil, da percepção ambiental, do consumo ecológico e preocupação dos pesquisados nas etapas da ACV; a terceira etapa identifica as discrepâncias entre as características ambientais existentes no produto e as que o consumidor efetivamente percebe; e por fim, a quarta etapa identifica as oportunidades de ações.

\section{METODOLOGIA}

O presente estudo se enquadra nos preceitos de pesquisa de caráter exploratório quantitativo, do tipo survey, considerando que objetiva verificar a percepção dos educandos de uma escola pública de grande porte do estado do Paraná em relação às ações do PNAE voltadas ao desenvolvimento sustentável.

Para que fosse possível a realização desse trabalho, se realizou um estudo bibliográfico referente aos temas: desenvolvimento sustentável; percepção, comportamento, educação ambiental, produtos orgânicos e PNAE. Com base nesse levantamento, o modelo Vapercom proposto por Brandalise (2008) foi escolhido por ter relação com a temática então proposta, vez que verifica a percepção e o comportamento de consumo; neste caso, dos educandos da referida escola.

Realizou-se, outrossim, uma pesquisa por meio da aplicação de questionários com 42 questões objetivas. Para o cálculo amostral, foi levantado, no colégio, o número total de educandos dos ensinos fundamental, médio e profissional, no ano de 2014, compreendendo que esta última modalidade de ensino se remete, no corpus deste trabalho, aos cursos técnicos de enfermagem e cuidados com a pessoa idosa.

A partir do levantamento desses dados, determinou-se o tamanho amostral (n), com possibilidade de erro amostral de 5\%, pela metodologia proposta por Barbetta, Reis e Bornia (2004), de modo que se obteve uma amostra de 999 indivíduos.

Após a coleta de dados, os questionários foram tabulados no software Excel. A etapa seguinte consistiu na realização de análise exploratória dos dados, a serem apresentados por meio de tabelas de distribuição percentuais e de forma descritiva, considerando, ao fazê-lo, as variáveis qualitativas exploradas.

\section{RESULTADOS E DISCUSSÃO}

\section{Caracterização dos Pesquisados}


A primeira etapa do modelo - caracterização do pesquisado - objetiva identificar o perfil do pesquisado em relação ao sexo, à idade, à renda familiar, à fonte de obtenção de informações sobre as questões ambientais, ao conhecimento sobre a ACV e ao impacto ambiental gerado pelo uso dos produtos.

O que se percebeu analisando o total dos entrevistados, é que, no ensino fundamental, $58 \%$ dos pesquisados são do gênero masculino e $42 \%$, do feminino; no ensino médio, $56 \%$ pertencem ao gênero masculino e $44 \%$, ao feminino. Considerando essa porcentagem no ensino profissional, no entanto, $92 \%$ dos entrevistados compõem o gênero feminino e somente $8 \%$, o masculino. Observa-se, dessa maneira, predominância do gênero masculino nos ensinos fundamental e médio, ao passo que, no ensino profissional, esse fenômeno é oposto, provavelmente devido ao fato de o público alvo desta categoria ser composto por alunos dos cursos técnicos de Enfermagem e Cuidados com a Pessoa Idosa, cuja predominância é feminina.

Procedendo-se à análise dos dados, na Tabela 1 dispõem-se os dados sobre a faixa etária dos pesquisados.

Tabela 1: Faixa etária dos pesquisados.

\begin{tabular}{lllllll}
\hline \multirow{2}{*}{ Fonte } & \multicolumn{2}{c}{ Ensino Fundamental } & \multicolumn{2}{c}{ Ensino Médio } & \multicolumn{2}{c}{ Ensino Profissional } \\
\cline { 2 - 7 } & No Respostas & $\mathbf{\%}$ & No Respostas & $\mathbf{\%}$ & No Respostas & \% \\
\hline Até 15 anos & 120 & 90 & 44 & 33 & 0 & 0 \\
Entre 16 e 20 anos & 13 & 10 & 89 & 67 & 18 & 13 \\
Entre 21 e 30 anos & 0 & 0 & 0 & 00 & 38 & 29 \\
Mais de 31 anos & 0 & 0 & 0 & 00 & 77 & 58 \\
\hline Total & $\mathbf{1 3 3}$ & $\mathbf{1 0 0 \%}$ & $\mathbf{1 3 3}$ & $\mathbf{1 0 0 \%}$ & $\mathbf{1 3 3}$ & $\mathbf{1 0 0 \%}$ \\
\hline
\end{tabular}

Em relação à idade, no ensino fundamental, 90\% dos pesquisados têm até 15 anos e $10 \%$ possuem idade entre 16 e 20 anos. No ensino médio, 67\% têm de 16 a 20 anos e 33\% possuem até 15 anos, ao passo que, no ensino profissional, 58\% dos entrevistados têm mais do que 31 anos, $29 \%$ estão entre 21 e 30 anos e $13 \%$, entre 16 e 20 anos.

Na Tabela 2, apresentam-se os dados sobre a fonte de obtenção de informações de questões ambientais.

Tabela 2: Fonte de obtenção de informações sobre questões ambientais.

\begin{tabular}{lllllll}
\hline \multirow{2}{*}{ Fonte } & \multicolumn{2}{l}{ Ensino Fundamental } & Ensino Médio & \multicolumn{2}{l}{ Ensino Profissional } \\
\cline { 2 - 7 } & No Respostas & \% & No Respostas & \% & No Respostas & \% \\
\hline Escola & 14 & 11 & 13 & 10 & 05 & 4 \\
Mídia & 85 & 64 & 82 & 61 & 109 & 82 \\
Família & 7 & 5 & 05 & 04 & 02 & 1 \\
Rótulos/Embalagens & 0 & 0 & 01 & 01 & 02 & 1 \\
Amigos & 0 & 0 & 01 & 01 & 01 & 1 \\
Redes sociais & 25 & 19 & 29 & 22 & 13 & 10 \\
Todas as opções & 2 & 1 & 02 & 01 & 01 & 1 \\
\hline Total & $\mathbf{1 3 3}$ & $\mathbf{1 0 0 \%}$ & $\mathbf{1 3 3}$ & $\mathbf{1 0 0 \%}$ & $\mathbf{1 3 3}$ & $\mathbf{1 0 0 \%}$ \\
\hline
\end{tabular}

Quanto à obtenção de informações sobre as questões ambientais, a maioria dos educandos dos ensinos fundamental, médio e profissional respondeu que têm acesso a essas notícias por meio de mídia, sendo a porcentagem correspondente a cada etapa de ensino $64 \%, 61 \%$ e $82 \%$, respectivamente. As redes 
sociais, a escola e a família foram apontadas como outras fontes de obtenção de informação, porém, com menor influência.

Na Tabela 3, ainda, são relacionados os dados referentes a com quem os entrevistados costumam comentar sobre questões ambientais.

Tabela 3: Com quem costumam comentar sobre questões ambientais.

\begin{tabular}{lllllll}
\hline \multirow{2}{*}{ Fonte } & \multicolumn{2}{l}{ Ensino Fundamental } & Ensino Médio & \multicolumn{3}{l}{ Ensino Profissional } \\
\cline { 2 - 7 } & $\mathbf{N}$ Respostas & $\mathbf{\%}$ & $\mathbf{N o}$ Respostas & $\mathbf{\%}$ & No Respostas & \% \\
\hline Amigos & 18 & 14 & 43 & 32 & 26 & 20 \\
Familiares & 49 & 37 & 48 & 36 & 73 & 55 \\
Rede social & 15 & 11 & 07 & 05 & 04 & 3 \\
Colegas & 11 & 8 & 09 & 07 & 23 & 17 \\
Com ninguém & 40 & 30 & 24 & 18 & 04 & 3 \\
Todas as opções & 0 & 0 & 02 & 02 & 03 & $\mathbf{2}$ \\
\hline Total & $\mathbf{1 3 3}$ & $\mathbf{1 0 0 \%}$ & $\mathbf{1 3 3}$ & $\mathbf{1 0 0 \%}$ & $\mathbf{1 3 3}$ & $\mathbf{1 0 0 \%}$ \\
\hline
\end{tabular}

Em todos os ensinos, vale observar, o maior percentual dos alunos respondeu conversar com familiares sobre as questões ambientais. Em contrapartida, a opção que atinge a possibilidade de não comentarem sobre o assunto com ninguém teve expressividade no resultado dos dados, alcançando, no ensino fundamental, $30 \%$ dos sujeitos, e, no ensino médio, $18 \%$.

Esse fator demonstra que muitos não têm o hábito de discutir sobre questões ambientais, seja por desconhecimento, seja por desinteresse. Tais dados apontam para a necessidade de "uma pedagogia centrada na compreensão da vida, uma experiência de aprendizagem no mundo real que supere a nossa alienação da natureza e reacenda o senso de participação e um currículo que ensine às nossas crianças os princípios básicos da ecologia" (CAPRA, 2008, p. 26).

Buscou-se saber, ainda, se os entrevistados sabem o que é Análise do Ciclo de Vida do Produto (ACV), cujo conceito somente é informado aos respondentes na Etapa 04. Na Tabela 4, portanto, são dispostos os dados sobre o conhecimento da ACV.

Os estudantes que compreendem o que é a $\mathrm{ACV}$ somam $5 \%, 8 \%$ e $33 \%$, respectivamente às modalidades de ensino supracitadas; os que, por outro lado, desconhecem, correspondem à proporção, também respectivamente, de $82 \%, 62 \%$ e $26 \%$. Os demais têm dúvidas sobre o que de fato significa a ACV.

Tabela 4: Conhecimento sobre a ACV.

\begin{tabular}{lllllll}
\hline \multirow{2}{*}{ Fonte } & \multicolumn{2}{l}{ Ensino Fundamental } & \multicolumn{2}{c}{ Ensino Médio } & \multicolumn{3}{c}{ Ensino Profissional } \\
\cline { 2 - 7 } & No Respostas & $\mathbf{\%}$ & No Respostas & \% & No Respostas & \% \\
\hline Sim & 07 & 5 & 11 & 8 & 44 & 33 \\
Têm dúvidas & 17 & 13 & 40 & 30 & 55 & 41 \\
Não & 109 & 82 & 82 & 62 & 34 & 26 \\
\hline Total & 133 & $\mathbf{1 0 0 \%}$ & $\mathbf{1 3 3}$ & $\mathbf{1 0 0 \%}$ & $\mathbf{1 3 3}$ & $\mathbf{1 0 0 \%}$ \\
\hline
\end{tabular}

Para concluir a primeira etapa, pesquisou-se sobre a noção dos educandos a respeito do impacto que os produtos utilizados geram ao meio ambiente. Os entrevistados que têm em mente esse aspecto correspondem a $85 \%$ dos alunos do ensino fundamental, $84 \%$ do ensino médio e $87 \%$ do ensino profissional. 
Os que, ao contrário, não fazem ideia dos impactos gerados alcançam a porcentagem de $7 \%$, 4\% e $4 \%$, respectivamente. Os demais têm dúvidas a respeito do assunto.

A segunda etapa pesquisa o levantamento da percepção ambiental dos entrevistados e é formada por questões que se referem às ações, à conduta ambiental no cotidiano, considerando os elementos redução/conservação de recursos no consumo, à reutilização e à reciclabilidade. Busca-se, ainda, verificar o grau de percepção e conduta do consumidor, considerando a variável ambiental em meio aos ensinos fundamental, médio e profissional, cujos resultados estão presentes, respectivamente, nas Tabelas 5, 6 e 7 .

Tabela 5: Frequência de respostas do conjunto percepção ambiental dos alunos do ensino fundamental.

\begin{tabular}{|c|c|c|c|c|c|}
\hline Conjunto 02 - Percepção Ambiental & Sempre & Frequentemente & $\begin{array}{l}\text { Algumas } \\
\text { vezes }\end{array}$ & $\begin{array}{l}\text { Pouquíssimas } \\
\text { vezes }\end{array}$ & Nunca \\
\hline $\begin{array}{l}\text { Antes de jogar alguma coisa no lixo, pensa em } \\
\text { como poderia reutilizá-la? }\end{array}$ & 16 & 15 & 37 & 26 & 39 \\
\hline É adepto à reciclagem? & 39 & 27 & 32 & 19 & 16 \\
\hline $\begin{array}{l}\text { Separa o lixo que pode ser reciclado e dispõe } \\
\text { para coleta? }\end{array}$ & 44 & 17 & 29 & 17 & 26 \\
\hline $\begin{array}{l}\text { Apaga as luzes, desliga a TV, o aparelho de } \\
\text { som, o ventilador/aquecedor quando sai do } \\
\text { ambiente? }\end{array}$ & 64 & 25 & 24 & 12 & 08 \\
\hline $\begin{array}{l}\text { Procura não deixar a torneira aberta ao } \\
\text { escovar os dentes ou ao fazer a barba? }\end{array}$ & 87 & 15 & 15 & 07 & 12 \\
\hline $\begin{array}{l}\text { Utiliza os dois lados dos papéis ou reutiliza } \\
\text { rascunhos? }\end{array}$ & 36 & 14 & 44 & 21 & 18 \\
\hline Evita imprimir coisas desnecessárias? & 55 & 18 & 17 & 17 & 26 \\
\hline Total & 341 & 131 & 198 & 119 & 145 \\
\hline
\end{tabular}

Tabela 6: Frequência de respostas do conjunto percepção ambiental dos alunos do ensino médio.

\begin{tabular}{|c|c|c|c|c|c|}
\hline Conjunto 02 - Percepção Ambiental & Sempre & Frequentemente & $\begin{array}{l}\text { Algumas } \\
\text { vezes }\end{array}$ & $\begin{array}{l}\text { Pouquíssimas } \\
\text { vezes }\end{array}$ & Nunca \\
\hline $\begin{array}{l}\text { Antes de jogar alguma coisa no lixo, } \\
\text { pensa em como poderia reutilizá-la? }\end{array}$ & 05 & 13 & 55 & 38 & 22 \\
\hline É adepto à reciclagem? & 33 & 34 & 31 & 21 & 14 \\
\hline $\begin{array}{l}\text { Separa o lixo que pode ser reciclado e } \\
\text { dispõe para coleta? }\end{array}$ & 35 & 25 & 26 & 24 & 23 \\
\hline $\begin{array}{l}\text { Apaga as luzes, desliga a TV, o } \\
\text { aparelho de som, } \\
\text { ventilador/aquecedor quando sai do } \\
\text { ambiente? }\end{array}$ & 79 & 33 & 08 & 07 & 06 \\
\hline $\begin{array}{l}\text { Procura não deixar a torneira aberta ao } \\
\text { escovar os dentes ou ao fazer a barba? }\end{array}$ & 104 & 09 & 11 & 02 & 07 \\
\hline $\begin{array}{l}\text { Utiliza os dois lados dos papéis ou } \\
\text { reutiliza rascunhos? }\end{array}$ & 35 & 44 & 37 & 09 & 08 \\
\hline Evita imprimir coisas desnecessárias? & 54 & 39 & 20 & 06 & 14 \\
\hline Total & 345 & 197 & 188 & 107 & 94 \\
\hline
\end{tabular}

Tabela 7: Frequência de respostas do conjunto percepção ambiental dos alunos do ensino profissional.

\begin{tabular}{llllll}
\hline Conjunto 02-Percepção Ambiental & Sempre & Frequentemente & $\begin{array}{l}\text { Algumas } \\
\text { vezes }\end{array}$ & $\begin{array}{l}\text { Pouquíssimas } \\
\text { vezes }\end{array}$ & Nunca \\
\hline $\begin{array}{l}\text { Antes de jogar alguma coisa no lixo, } \\
\text { pensa em como poderia reutilizá-la? }\end{array}$ & 44 & 23 & 46 & 16 & 04
\end{tabular}




\begin{tabular}{|c|c|c|c|c|c|}
\hline É adepto à reciclagem? & 67 & 23 & 27 & 08 & 08 \\
\hline $\begin{array}{l}\text { Separa o lixo que pode ser reciclado e } \\
\text { dispõe para coleta? }\end{array}$ & 67 & 27 & 25 & 05 & 09 \\
\hline $\begin{array}{l}\text { Apaga as luzes, desliga a TV, o } \\
\text { aparelho de som, } \\
\text { ventilador/aquecedor quando sai do } \\
\text { ambiente? }\end{array}$ & 92 & 22 & 12 & 02 & 05 \\
\hline $\begin{array}{l}\text { Procura não deixar a torneira aberta ao } \\
\text { escovar os dentes ou ao fazer a barba? }\end{array}$ & 96 & 19 & 11 & 02 & 05 \\
\hline $\begin{array}{l}\text { Utiliza os dois lados dos papéis ou } \\
\text { reutiliza rascunhos? }\end{array}$ & 67 & 25 & 30 & 06 & 05 \\
\hline Evita imprimir coisas desnecessárias? & 83 & 23 & 08 & 12 & 07 \\
\hline Total & 516 & 162 & 159 & 51 & 43 \\
\hline
\end{tabular}

Em relação à percepção ambiental, a predominância que insurge nos três ensinos é a relacionada ao comportamento de nunca deixar a torneira aberta ao escovar os dentes e fazer a barba. Em contrapartida, antes de jogar algo no lixo, poucas vezes pensam em como poderiam reutilizar esse mesmo lixo.

A fim de obter o grau de percepção ambiental dos respondentes, realizou-se o sistema de alocação de pesos das possíveis respostas, a partir de uma escala de 0 a 4, em que 0 equivale à frequência "nunca" e 4, à "sempre". Dessa forma, o número de respostas em cada item foi multiplicado por seu respectivo peso e dividido pelo número total de questões para cada nível de ensino, obtendo, assim, o grau de percepção em relação às questões ambientais, conforme demonstrado na Tabela 8:

Tabela 8: Alocação de pesos e elaboração do grau de percepção ambiental.

\begin{tabular}{lllllll}
\hline \multicolumn{2}{l}{ a) No de Respostas } & & b) Valores & \multicolumn{2}{l}{$(\mathbf{a} \mathbf{x}$ b) Resultado } \\
\hline $\begin{array}{l}\text { Ensino } \\
\text { Fundamental }\end{array}$ & $\begin{array}{l}\text { Ensino } \\
\text { Médio }\end{array}$ & $\begin{array}{l}\text { Ensino } \\
\text { Profissional }\end{array}$ & & Ensino & $\begin{array}{l}\text { Ensino } \\
\text { Médio }\end{array}$ & $\begin{array}{l}\text { Ensino } \\
\text { Profissional }\end{array}$ \\
\hline $\mathrm{A}=345$ & $\mathrm{~A}=341$ & $\mathrm{~A}=516$ & 4 & 1364 & 1380 & 2064 \\
$\mathrm{~B}=197$ & $\mathrm{~B}=131$ & $\mathrm{~B}=162$ & 3 & 393 & 591 & 486 \\
$\mathrm{C}=188$ & $\mathrm{C}=198$ & $\mathrm{C}=159$ & 2 & 396 & 376 & 318 \\
$\mathrm{D}=107$ & $\mathrm{D}=119$ & $\mathrm{D}=51$ & 1 & 119 & 107 & 51 \\
$\mathrm{E}=94$ & $\mathrm{E}=145$ & $\mathrm{E}=43$ & 0 & 0 & 94 & 0 \\
\hline (c) Soma dos resultados & & & $\mathbf{2 2 7 2}$ & $\mathbf{2 5 4 8}$ & $\mathbf{2 9 1 9}$ \\
\hline (d) Número de questões & & $\mathbf{9 3 1}$ & $\mathbf{2 , 7 4}$ \\
\hline (e=c/d) Resultado & & $\mathbf{2 , 4 3}$ & $\mathbf{3 , 1 4}$ \\
\hline
\end{tabular}

A classificação do grau de percepção pode ser melhor visualizada na Tabela 9.

Tabela 9: Classificação do grau de percepção ambiental.

\begin{tabular}{ll}
\hline Grau de percepção em relação às questões ambientais & Valores \\
\hline A) Possui alta percepção ambiental & Entre 3,3 e 4,0 \\
B) Possui percepção ambiental & Entre 2,5 e 3,2 \\
C) Possui potenciais traços de percepção ambiental & Entre 1,7 e 2,4 \\
D) Possui poucos traços de percepção ambiental & Entre 0,9 e 1,6 \\
E) Não possui percepção ecológica & Até 0,8 \\
\hline
\end{tabular}
Fonte: Brandalise (2008).

Segundo a Tabela 8, e, de acordo com a classificação exposta pela Tabela 9, observa-se que os educandos do ensino fundamental 'possuem potenciais traços de percepção ambiental', enquanto os do ensino médio e profissional 'possuem percepção ambiental'. 
A terceira etapa do modelo identifica a conduta de compra/consumo dos respondentes em relação aos produtos ecologicamente corretos - nesse contexto entendidos como o produto que prejudica minimamente o meio ambiente -, nas principais etapas do ciclo de vida, na aquisição e no processamento de matérias primas, na utilização, na pós-utilização e no descarte, considerando a extração de matéria prima, o transporte, o consumo de energia, a vida útil, a biodegradabilidade e a reciclabilidade.

Os dados sobre o conjunto ecológico são apresentados nas Tabelas 10, 11 e 12.

Tabela 10: Frequência de respostas do conjunto consumo ecológico do ensino fundamental.

\begin{tabular}{|c|c|c|c|c|c|}
\hline Conjunto 03 - Consumo Ecológico & Sempre & Frequentemente & AlgumasVezes & $\begin{array}{l}\text { Pouquíssimas } \\
\text { vezes }\end{array}$ & Nunca \\
\hline $\begin{array}{l}\text { Considera a variável ambiental quando } \\
\text { da compra de um produto? }\end{array}$ & 17 & 19 & 21 & 23 & 53 \\
\hline $\begin{array}{l}\text { Ao comprar, se deixa influenciar pela } \\
\text { propaganda, pelos amigos ou pela } \\
\text { família, em relação às questões } \\
\text { ambientais? }\end{array}$ & 19 & 28 & 35 & 19 & 32 \\
\hline $\begin{array}{l}\text { Ao comprar, procura saber se o } \\
\text { fabricante pratica ações ambientais } \\
\text { adequadas? }\end{array}$ & 10 & 12 & 18 & 18 & 75 \\
\hline $\begin{array}{l}\text { Ao comprar, valoriza o fabricante que } \\
\text { tem a 'postura' ecologicamente } \\
\text { correta? }\end{array}$ & 18 & 17 & 28 & 21 & 49 \\
\hline $\begin{array}{l}\text { Antes da compra, verifica rótulos e } \\
\text { embalagens, para identificar os } \\
\text { 'produtos' ecologicamente corretos? }\end{array}$ & 18 & 10 & 19 & 28 & 58 \\
\hline $\begin{array}{l}\text { Procura comprar produtos e/ou } \\
\text { embalagens fabricados com material } \\
\text { reciclado ou que têm potencial para } \\
\text { serem reciclados? }\end{array}$ & 18 & 13 & 30 & 25 & 47 \\
\hline $\begin{array}{l}\text { Verifica o consumo de energia quando } \\
\text { da compra de um produto? }\end{array}$ & 29 & 15 & 25 & 18 & 46 \\
\hline Compra produtos biodegradáveis? & 19 & 20 & 32 & 26 & 36 \\
\hline $\begin{array}{l}\text { Dispõe-se a pagar mais por um } \\
\text { produto ecologicamente correto? }\end{array}$ & 27 & 12 & 39 & 21 & 33 \\
\hline $\begin{array}{l}\text { Dispõe-se a mudar de marca de } \\
\text { produto para auxiliar junto à } \\
\text { conservação do meio ambiente? }\end{array}$ & 23 & 27 & 21 & 25 & 37 \\
\hline $\begin{array}{l}\text { Pagaria mais por um alimento } \\
\text { orgânico? }\end{array}$ & 21 & 22 & 26 & 21 & 43 \\
\hline Total & 219 & 195 & 294 & 245 & 509 \\
\hline
\end{tabular}

Tabela 11: Frequência de respostas do conjunto consumo ecológico do ensino médio.

\begin{tabular}{|c|c|c|c|c|c|}
\hline Conjunto 03 - Consumo Ecológico & Sempre & Frequentemente & $\begin{array}{l}\text { Algumas } \\
\text { Vezes }\end{array}$ & $\begin{array}{l}\text { Pouquíssimas } \\
\text { Vezes }\end{array}$ & Nunca \\
\hline $\begin{array}{l}\text { Considera a variável ambiental quando } \\
\text { da compra de um produto? }\end{array}$ & 05 & 15 & 42 & 35 & 36 \\
\hline $\begin{array}{l}\text { Ao comprar, se deixa influenciar pela } \\
\text { propaganda, pelos amigos ou pela } \\
\text { família, em relação às questões } \\
\text { ambientais? }\end{array}$ & 04 & 20 & 40 & 39 & 30 \\
\hline $\begin{array}{l}\text { Ao comprar, procura saber se o } \\
\text { fabricante pratica ações ambientais }\end{array}$ & 08 & 02 & 11 & 40 & 72 \\
\hline
\end{tabular}


adequadas?

Ao comprar, valoriza o fabricante que tem a 'postura' ecologicamente

17

30

22

19

correta?

Antes da compra, verifica rótulos e embalagens, para identificar 'produto' ecologicamente corretos?

Procura comprar produtos e/ou embalagens fabricados com material reciclado ou que têm potencial para serem reciclados?

Verifica o consumo de energia quando da compra de um produto?

Compra produtos biodegradáveis?

Dispõe-se a pagar mais por um produto ecologicamente correto?

Dispõe-se a mudar de marca de produto para auxiliar à conservação do meio ambiente?

07

11

20

42

53

05

18

34

40

36

31

29

16

24

33

$06 \quad 37$

16

18

43

25

22

24

26

23

44

31

24

21

Pagaria mais por um alimento orgânico?

Total 30

155 23 36 15 29

226

347

334

401

Tabela 12: Frequência de respostas do conjunto consumo ecológico do ensino profissional.

\begin{tabular}{|c|c|c|c|c|c|}
\hline Conjunto 03 - Consumo Ecológico & Sempre & Frequentemente & $\begin{array}{l}\text { Algumas } \\
\text { Vezes }\end{array}$ & $\begin{array}{l}\text { Pouquíssimas } \\
\text { Vezes }\end{array}$ & Nunca \\
\hline $\begin{array}{l}\text { Considera a variável ambiental quando } \\
\text { da compra de um produto? }\end{array}$ & 32 & 18 & 54 & 08 & 21 \\
\hline $\begin{array}{l}\text { Ao comprar, se deixa influenciar pela } \\
\text { propaganda, pelos amigos ou pela } \\
\text { família, em relação às questões } \\
\text { ambientais? }\end{array}$ & 09 & 13 & 35 & 35 & 41 \\
\hline $\begin{array}{l}\text { Ao comprar, procura saber se o } \\
\text { fabricante pratica ações ambientais } \\
\text { adequadas? }\end{array}$ & 17 & 07 & 27 & 33 & 49 \\
\hline $\begin{array}{l}\text { Ao comprar, valoriza o fabricante que } \\
\text { tem 'postura' ecologicamente correta? }\end{array}$ & 25 & 24 & 33 & 18 & 33 \\
\hline $\begin{array}{l}\text { Antes da compra, verifica rótulos e } \\
\text { embalagens, para identificar } \\
\text { 'produtos' ecologicamente corretos? }\end{array}$ & 27 & 13 & 33 & 33 & 27 \\
\hline $\begin{array}{l}\text { Procura comprar produtos e/ou } \\
\text { embalagens fabricados com material } \\
\text { reciclado ou que têm potencial para } \\
\text { serem reciclados? }\end{array}$ & 26 & 19 & 35 & 26 & 27 \\
\hline $\begin{array}{l}\text { Verifica o consumo de energia quando } \\
\text { da compra de um produto? }\end{array}$ & 65 & 30 & 10 & 13 & 15 \\
\hline Compra produtos biodegradáveis? & 24 & 27 & 39 & 28 & 14 \\
\hline $\begin{array}{l}\text { Dispõe-se a pagar mais por um produto } \\
\text { ecologicamente correto? }\end{array}$ & 24 & 32 & 40 & 22 & 13 \\
\hline $\begin{array}{l}\text { Dispõe-se a mudar de marca de } \\
\text { produto para auxiliar à conservação do } \\
\text { meio ambiente? }\end{array}$ & 46 & 26 & 43 & 05 & 11 \\
\hline $\begin{array}{l}\text { Pagaria mais por um alimento } \\
\text { orgânico? }\end{array}$ & 41 & 28 & 37 & 18 & 07 \\
\hline Total & 336 & 237 & 386 & 239 & 258 \\
\hline
\end{tabular}


Pode-se observar, por meio das Tabelas 10, 11 e 12, que, em relação ao consumo ecológico no ensino fundamental, não existe preocupação representativa em relação às questões suscitadas, enquanto nos ensinos médio e profissional, percebem-se, ao menos, pequenos sinais de atenção a algumas questões desse conjunto.

Tabela 13: Alocação de pesos e elaboração do grau de consumo ecológico.

\begin{tabular}{lllllll}
\hline a) No respostas & & & b) Valores & \multicolumn{2}{l}{$(\mathbf{a} \mathbf{x}$ b) Resultado } \\
\hline $\begin{array}{l}\text { Ensino } \\
\text { Fundamental }\end{array}$ & $\begin{array}{l}\text { Ensino } \\
\text { Médio }\end{array}$ & $\begin{array}{l}\text { Ensino } \\
\text { Profissional }\end{array}$ & & $\begin{array}{l}\text { Ensino } \\
\text { Fundamental }\end{array}$ & Ensino Médio & $\begin{array}{l}\text { Ensino } \\
\text { Profissional }\end{array}$ \\
\hline $\mathrm{A}=219$ & $\mathrm{~A}=155$ & $\mathrm{~A}=336$ & 4 & 876 & 620 & 1344 \\
$\mathrm{~B}=195$ & $\mathrm{~B}=226$ & $\mathrm{~B}=237$ & 3 & 585 & 678 & 711 \\
$\mathrm{C}=294$ & $\mathrm{C}=347$ & $\mathrm{C}=386$ & 2 & 588 & 694 & 772 \\
$\mathrm{D}=245$ & $\mathrm{D}=334$ & $\mathrm{D}=239$ & 1 & 245 & 334 & 239 \\
$\mathrm{E}=509$ & $\mathrm{E}=401$ & $\mathrm{E}=258$ & 0 & 0 & 0 & 0 \\
\hline (c) Soma dos resultados & & & $\mathbf{2 2 9 4}$ & $\mathbf{2 3 2 6}$ & $\mathbf{3 0 6 6}$ \\
\hline (d) Número de questões & & $\mathbf{1 4 6 2}$ & $\mathbf{1 1 2 9}$ & $\mathbf{1 4 5 6}$ \\
\hline (e=c/d) Resultado & & $\mathbf{1 , 5 7}$ & $\mathbf{2 , 0 6}$ & $\mathbf{2 , 1 1}$ \\
\hline
\end{tabular}

Conforme demonstrado na Tabela 13, e, de acordo com a Tabela 9, os educandos do ensino fundamental 'possuem poucos traços de percepção ambiental'. Nesse mesmo sentido, segundo a classificação observada pela Tabela 9, os alunos do ensino médio e do profissional 'possuem traços de percepção ambiental'.

A escola objeto da presente pesquisa prepara a merenda escolar com alimentos orgânicos. A partir dessa informação, buscou-se saber se os educandos têm conhecimento acerca dessa prática. A Tabela 14, nesse contexto, apresenta o resultado da questão referente ao conhecimento da utilização de alimentos orgânicos.

Tabela 14: Noção do aluno acerca da utilização de alimentos orgânicos na preparação da merenda escolar no colégio em que estuda.

\begin{tabular}{lllllll}
\hline \multirow{2}{*}{ Fonte } & Ensino Fundamental & \multicolumn{3}{c}{ Ensino Médio } & \multicolumn{2}{c}{ Ensino Profissional } \\
\cline { 2 - 7 } & No Respostas & \% & No Respostas & \% & No Respostas & \% \\
\hline Sim & 28 & 21 & 25 & 19 & 33 & 25 \\
Não & 105 & 79 & 108 & 81 & 100 & 75 \\
\hline Total & $\mathbf{1 3 3}$ & $\mathbf{1 0 0 \%}$ & $\mathbf{1 3 3}$ & $\mathbf{1 0 0 \%}$ & $\mathbf{1 3 3}$ & $\mathbf{1 0 0 \%}$ \\
\hline
\end{tabular}

A respeito do que versa sobre o conhecimento frente à utilização de alimentos orgânicos na preparação da merenda escolar, os educandos que têm conhecimento a essa informação correspondem a $21 \%, 19 \%$ e $25 \%$, respectivamente à gradação da escala de ensinos (fundamental, médio e profissional). Em contrapartida, os que não sabem sobre a procedência dos mesmos somam $79 \%$, $81 \%$ e $75 \%$, também respectivamente.

A Tabela 15, por sua vez, apresenta o resultado da questão sobre a compreensão, por parte dos estudantes, a respeito de uma alimentação livre de agrotóxicos.

Tabela 15: Compreensão, por parte dos estudantes, a respeito de uma alimentação livre agrotóxicos.

\begin{tabular}{lllllll}
\hline Fonte & \multicolumn{2}{l}{ Ensino Fundamental } & \multicolumn{2}{c}{ Ensino Médio } & \multicolumn{2}{c}{ Ensino Profissional } \\
\cline { 2 - 7 } & No Respostas & $\%$ & No Respostas & $\%$ & № Respostas & $\%$ \\
\hline Sim, totalmente & 48 & 36 & 50 & 38 & 84 & 63
\end{tabular}




\begin{tabular}{lllllll} 
Sim, parcialmente & 49 & 37 & 52 & 39 & 32 & 24 \\
Tenho dúvidas & 30 & 23 & 24 & 18 & 17 & 13 \\
Não & 06 & 04 & 07 & 5 & 00 & 0 \\
\hline Total & $\mathbf{1 3 3}$ & $\mathbf{1 0 0 \%}$ & $\mathbf{1 3 3}$ & $\mathbf{1 0 0 \%}$ & $\mathbf{1 3 3}$ & $\mathbf{1 0 0 \%}$ \\
\hline
\end{tabular}

Os dados que refletem a noção sobre uma alimentação livre de agrotóxicos demonstram que os educandos que sabem desse fato compõem 36\%, 38\% e 63\% respectivamente (ensinos fundamental, médio e profissional). Por outro lado, responderam que não sabem disso $4 \%$ do total de alunos do ensino fundamental e $5 \%$ do ensino médio. 0 restante dos educandos tem dúvidas com relação a esse assunto.

Para concluir segue-se para a quarta etapa, a qual apresenta a frequência das respostas do conjunto referente à $\mathrm{ACV}$, as quais são apresentadas nas Tabelas 16, 17 e 18.

Tabela 16: Frequência de respostas do conjunto de etapas da ACV do ensino fundamental.

\begin{tabular}{|c|c|c|c|c|c|}
\hline $\begin{array}{l}\text { Conjunto } 04 \text { - Etapas } \\
\text { da ACV }\end{array}$ & $\begin{array}{l}\text { Forte } \\
\text { preocupação }\end{array}$ & $\begin{array}{l}\text { Frequentemente } \\
\text { me preocupo }\end{array}$ & $\begin{array}{l}\text { Média } \\
\text { preocupação }\end{array}$ & $\begin{array}{l}\text { Fraca } \\
\text { preocupação }\end{array}$ & $\begin{array}{l}\text { Nenhuma } \\
\text { preocupação }\end{array}$ \\
\hline \multicolumn{6}{|c|}{ Em relação à matéria prima, indique o grau de preocupação com a/o: } \\
\hline $\begin{array}{l}\text { Origem dos recursos } \\
\text { (se são renováveis ou } \\
\text { não) }\end{array}$ & 31 & 22 & 34 & 29 & 17 \\
\hline $\begin{array}{l}\text { Impacto ambiental na } \\
\text { extração (e no } \\
\text { transporte) }\end{array}$ & 31 & 28 & 39 & 24 & 11 \\
\hline Total Parcial & 62 & 50 & 73 & 53 & 28 \\
\hline \multicolumn{6}{|c|}{ Em relação ao processo de produção, indique o grau de preocupação com a/o: } \\
\hline $\begin{array}{l}\text { Consumo de energia } \\
\text { (na produção) }\end{array}$ & 32 & 33 & 32 & 14 & 22 \\
\hline $\begin{array}{l}\text { Geração de resíduos } \\
\text { sólidos, efluentes } \\
\text { líquidos e emissões } \\
\text { atmosféricas }\end{array}$ & 32 & 36 & 28 & 20 & 17 \\
\hline $\begin{array}{lr}\text { Consumo } & \text { de } \\
\text { combustível } & \text { na } \\
\text { armazenagem } & \text { e/ou } \\
\text { transporte } & \text { e } \\
\text { distribuição } & \\
\end{array}$ & 29 & 25 & 30 & 19 & 30 \\
\hline Total Parcial & 93 & 94 & 90 & 53 & 69 \\
\hline \multicolumn{6}{|c|}{ Em relação à utilização do produto, indique o grau de preocupação com a/o: } \\
\hline Vida útil do produto & 39 & 39 & 24 & 14 & 17 \\
\hline $\begin{array}{l}\text { Necessidade de } \\
\text { energia }\end{array}$ & 48 & 20 & 35 & 20 & 10 \\
\hline $\begin{array}{l}\text { Potencial } \\
\text { contaminação ao } \\
\text { meio ambiente }\end{array}$ & 40 & 33 & 31 & 14 & 15 \\
\hline $\begin{array}{ll}\text { Embalagem } & \text { (tipo } \\
\text { e/ou volume) } & \\
\end{array}$ & 22 & 34 & 26 & 17 & 34 \\
\hline Total Parcial & 149 & 126 & 116 & 65 & 76 \\
\hline \multicolumn{6}{|c|}{ Em relação à pós-utilização do produto, indique o grau de preocupação com a/o: } \\
\hline $\begin{array}{l}\text { Possibilidade de } \\
\text { reutilização }\end{array}$ & 30 & 29 & 34 & 16 & 24 \\
\hline $\begin{array}{l}\text { Potencialidade de } \\
\text { reaproveitamento de } \\
\text { componentes }\end{array}$ & 22 & 20 & 38 & 29 & 24 \\
\hline $\begin{array}{l}\text { Possibilidade } \\
\text { reciclagem }\end{array}$ & 36 & 28 & 28 & 21 & 20 \\
\hline Total Parcial & 88 & 77 & 100 & 66 & 68 \\
\hline
\end{tabular}


Em relação ao descarte do produto, indique o grau de preocupação com a/o:

Periculosidade ou 43

25

27

19

19

toxidade

Volume do material 27

29

37

16

24

(incluindo

embalagem)

\begin{tabular}{llllll} 
Biodegradabilidade & 34 & 28 & 31 & 17 & 23 \\
\hline Total Parcial & 104 & $\mathbf{8 2}$ & $\mathbf{9 5}$ & 52 & 66 \\
\hline Total Geral & 496 & 429 & 474 & 289 & 307
\end{tabular}

Tabela 17: Frequência de respostas do conjunto de etapas da ACV do ensino médio.

\begin{tabular}{|c|c|c|c|c|c|}
\hline $\begin{array}{l}\text { Conjunto } 04 \text { - Etapas } \\
\text { da ACV }\end{array}$ & $\begin{array}{l}\text { Forte } \\
\text { preocupação }\end{array}$ & $\begin{array}{l}\text { Frequentemente } \\
\text { me preocupo }\end{array}$ & $\begin{array}{l}\text { Média } \\
\text { preocupação }\end{array}$ & $\begin{array}{l}\text { Fraca } \\
\text { preocupação }\end{array}$ & $\begin{array}{l}\text { Nenhuma } \\
\text { preocupação }\end{array}$ \\
\hline \multicolumn{6}{|c|}{ Em relação à matéria prima, indique o grau de preocupação com a/o: } \\
\hline $\begin{array}{l}\text { Origem dos recursos } \\
\text { (se são renováveis ou } \\
\text { não) }\end{array}$ & 13 & 34 & 51 & 30 & 05 \\
\hline $\begin{array}{l}\text { Impacto ambiental na } \\
\text { extração (e no } \\
\text { transporte) }\end{array}$ & 26 & 36 & 40 & 20 & 11 \\
\hline Total Parcial & 39 & 70 & 91 & 50 & 16 \\
\hline \multicolumn{6}{|c|}{ Em relação ao processo de produção, indique o grau de preocupação com a/o: } \\
\hline $\begin{array}{l}\text { Consumo de energia } \\
\text { (na produção) }\end{array}$ & 37 & 37 & 36 & 17 & 06 \\
\hline $\begin{array}{l}\text { Geração de resíduos } \\
\text { sólidos, efluentes } \\
\text { líquidos e emissões } \\
\text { atmosféricas }\end{array}$ & 35 & 36 & 32 & 24 & 06 \\
\hline $\begin{array}{lr}\text { Consumo } & \text { de } \\
\text { combustível } & \text { na } \\
\text { armazenagem } & \text { e/ou } \\
\text { transporte } & \text { e } \\
\text { distribuição } & \end{array}$ & 27 & 26 & 38 & 29 & 13 \\
\hline Total Parcial & 99 & 99 & 106 & 70 & 25 \\
\hline
\end{tabular}

Em relação à utilização do produto, indique o grau de preocupação com a/o:

$\begin{array}{llllll}\text { Vida útil do produto } & 36 & \mathbf{4 5} & 32 & 14 & 06 \\ \begin{array}{l}\text { Necessidade } \\ \text { energia }\end{array} & \mathbf{4 1} & \mathbf{4 3} & 31 & 12 & 06\end{array}$

$\begin{array}{llllll}\text { Potencial } & 47 & 37 & 28 & 16 & 05\end{array}$

contaminação ao meio

ambiente

Embalagem (tipo e/ou

$\begin{array}{lll}27 & 34 & 36\end{array}$

36

22

14

\begin{tabular}{|c|c|c|c|c|c|c|}
\hline Total Parcial & & 151 & 159 & 127 & 64 & 31 \\
\hline \multicolumn{7}{|c|}{ Em relação à pós-utilização do produto, indique o grau de preocupação com a/o: } \\
\hline $\begin{array}{l}\text { Possibilidade } \\
\text { reutilização }\end{array}$ & de & 25 & 48 & 32 & 14 & 14 \\
\hline $\begin{array}{l}\text { Potencialidade } \\
\text { reaproveitamento } \\
\text { componentes }\end{array}$ & $\begin{array}{l}\text { de } \\
\text { de }\end{array}$ & 17 & 38 & 43 & 24 & 11 \\
\hline $\begin{array}{l}\text { Possibilidade } \\
\text { reciclagem }\end{array}$ & de & 30 & 51 & 20 & 23 & 09 \\
\hline Total Parcial & & 72 & 137 & 95 & 61 & 34 \\
\hline \multicolumn{7}{|c|}{ Em relação ao descarte do produto, indique o grau de preocupação com a/o: } \\
\hline $\begin{array}{l}\text { Periculosidade } \\
\text { toxidade }\end{array}$ & ou & 48 & 26 & 33 & 18 & 08 \\
\hline $\begin{array}{l}\text { Volume de mater } \\
\text { (incluindo }\end{array}$ & & 18 & 28 & 42 & 33 & 12 \\
\hline
\end{tabular}


embalagem)

\begin{tabular}{llllll} 
Biodegradabilidade & 33 & 27 & 42 & 23 & 08 \\
\hline Total Parcial & 99 & $\mathbf{8 1}$ & $\mathbf{1 1 7}$ & $\mathbf{7 4}$ & 28 \\
\hline Total Geral & $\mathbf{4 6 0}$ & $\mathbf{5 4 6}$ & 536 & 319 & 134 \\
\hline
\end{tabular}

Tabela 18: Frequência de respostas do conjunto de etapas da ACV do ensino profissional.

\begin{tabular}{|c|c|c|c|c|c|}
\hline $\begin{array}{l}\text { Conjunto } 04 \text { - Etapas } \\
\text { ACV }\end{array}$ & $\begin{array}{l}\text { Forte } \\
\text { preocupação }\end{array}$ & $\begin{array}{l}\text { Frequentemente } \\
\text { me preocupo }\end{array}$ & $\begin{array}{l}\text { Média } \\
\text { preocupação }\end{array}$ & $\begin{array}{l}\text { Fraca } \\
\text { preocupação }\end{array}$ & $\begin{array}{l}\text { Nenhuma } \\
\text { preocupação }\end{array}$ \\
\hline \multicolumn{6}{|c|}{ Em relação à matéria prima, indique o grau de preocupação com a/o: } \\
\hline $\begin{array}{l}\text { Origem dos recursos } \\
\text { (se são renováveis ou } \\
\text { não) }\end{array}$ & 49 & 46 & 23 & 11 & 04 \\
\hline $\begin{array}{l}\text { Impacto ambiental na } \\
\text { extração (e no } \\
\text { transporte) }\end{array}$ & 52 & 45 & 20 & 15 & 01 \\
\hline Total Parcial & 101 & 91 & 43 & 26 & 05 \\
\hline \multicolumn{6}{|c|}{ Em relação ao processo de produção, indique o grau de preocupação com a/o: } \\
\hline $\begin{array}{l}\text { Consumo de energia } \\
\text { (na produção) }\end{array}$ & 65 & 29 & 25 & 10 & 04 \\
\hline $\begin{array}{l}\text { Geração de resíduos } \\
\text { sólidos, efluentes } \\
\text { líquidos e emissões } \\
\text { atmosféricas }\end{array}$ & 64 & 36 & 19 & 11 & 03 \\
\hline $\begin{array}{lr}\text { Consumo } & \text { de } \\
\text { combustível } & \text { na } \\
\text { armazenagem } & \text { e/ou } \\
\text { transporte } & \text { e } \\
\text { distribuição } & \end{array}$ & 53 & 35 & 28 & 16 & 01 \\
\hline Total Parcial & 182 & 100 & 72 & 37 & 08 \\
\hline
\end{tabular}

Em relação à utilização do produto, indique o grau de preocupação com a/o:

\begin{tabular}{|c|c|c|c|c|c|}
\hline Vida útil do produto & 63 & 47 & 15 & 07 & 01 \\
\hline $\begin{array}{l}\text { Necessidade } \\
\text { energia }\end{array}$ & 61 & 48 & 13 & 10 & 01 \\
\hline $\begin{array}{l}\text { Potencial } \\
\text { contaminação } \\
\text { meio ambiente }\end{array}$ & 74 & 34 & 15 & 06 & 03 \\
\hline $\begin{array}{l}\text { Embalagem (tipo e/ou } \\
\text { volume) }\end{array}$ & 43 & 50 & 21 & 12 & 06 \\
\hline Total Parcial & 241 & 179 & 64 & 35 & 11 \\
\hline
\end{tabular}

\begin{tabular}{|c|c|c|c|c|c|}
\hline \multicolumn{6}{|c|}{ Em relação à pós-utilização do produto, indique o grau de preocupação com a/o: } \\
\hline $\begin{array}{l}\text { Possibilidade } \\
\text { reutilização }\end{array}$ & 59 & 47 & 19 & 06 & 02 \\
\hline $\begin{array}{l}\text { Potencialidade de } \\
\text { reaproveitamento de } \\
\text { componentes }\end{array}$ & 45 & 49 & 27 & 10 & 01 \\
\hline $\begin{array}{l}\text { Possibilidade de } \\
\text { reciclagem }\end{array}$ & 67 & 40 & 16 & 05 & 04 \\
\hline Total Parcial & 171 & 136 & 62 & 21 & 07 \\
\hline \multicolumn{6}{|c|}{ Em relação ao descarte do produto, indique o grau de preocupação com a/o: } \\
\hline $\begin{array}{l}\text { Periculosidade ou } \\
\text { toxidade }\end{array}$ & 94 & 21 & 10 & 05 & 02 \\
\hline $\begin{array}{l}\text { Volume de material } \\
\text { (incluindo } \\
\text { embalagem) }\end{array}$ & 56 & 48 & 19 & 05 & 04 \\
\hline Biodegradabilidade & 65 & 37 & 20 & 08 & 02 \\
\hline Total Parcial & 215 & 106 & 49 & 18 & 08 \\
\hline Total Geral & 910 & 612 & 290 & 137 & 39 \\
\hline
\end{tabular}


Pode-se observar, a partir das análises das Tabelas 16, 17 e 18, que, em relação às etapas da ACV, a preocupação é maior no ensino profissional, à medida que se nota, no ensino fundamental e médio, uma preocupação menor em relação às questões desse conjunto.

Tabela 19: Alocação de pesos e elaboração do grau de preocupação em relação à ACV.

\begin{tabular}{lllllll}
\hline \multicolumn{2}{l}{ a) Número de respostas } & & b) Valores & (a x b) Resultado & \\
\hline $\begin{array}{l}\text { Ensino } \\
\text { Fundamental }\end{array}$ & $\begin{array}{l}\text { Ensino } \\
\text { Médio }\end{array}$ & $\begin{array}{l}\text { Ensino } \\
\text { Profissional }\end{array}$ & & $\begin{array}{l}\text { Ensino } \\
\text { Fundamental }\end{array}$ & $\begin{array}{l}\text { Ensino } \\
\text { Médio }\end{array}$ & $\begin{array}{l}\text { Ensino } \\
\text { Profissional }\end{array}$ \\
\hline $\mathrm{A}=496$ & $\mathrm{~A}=460$ & $\mathrm{~A}=910$ & 4 & 1984 & 1840 & 3640 \\
$\mathrm{~B}=429$ & $\mathrm{~B}=546$ & $\mathrm{~B}=612$ & 3 & 1287 & 1638 & 1836 \\
$\mathrm{C}=474$ & $\mathrm{C}=536$ & $\mathrm{C}=290$ & 2 & 948 & 1072 & 580 \\
$\mathrm{D}=289$ & $\mathrm{D}=319$ & $\mathrm{D}=137$ & 1 & 289 & 319 & 137 \\
$\mathrm{E}=307$ & $\mathrm{E}=134$ & $\mathrm{E}=39$ & 0 & 0 & 0 & 0 \\
\hline (c) Soma dos resultados & & & $\mathbf{4 5 0 8}$ & $\mathbf{4 8 6 9}$ & $\mathbf{6 1 9 3}$ \\
\hline (d) Número de questões & & & $\mathbf{1 9 9 5}$ & $\mathbf{1 9 9 5}$ & $\mathbf{1 9 8 8}$ \\
\hline (e=c/d) Resultado & & $\mathbf{2 , 2 6}$ & $\mathbf{2 , 4 4}$ & $\mathbf{3 , 1 2}$ \\
\hline
\end{tabular}

Consoante à classificação da Tabela 9, e, corroborando com o disposto pela Tabela 19, é perceptível que os educandos do ensino fundamental e médio 'possuem potenciais traços de percepção ambiental', na proporção em que os estudantes do ensino profissional 'possuem percepção ambiental'.

\section{CONSIDERAÇÕES FINAIS}

Esse trabalho teve como objetivo principal pesquisar a percepção dos educandos de uma escola pública de grande porte a respeito das ações do Programa Nacional de Alimentação Escolar (PNAE) voltadas ao desenvolvimento sustentável.

A partir dos resultados obtidos, pode-se observar que a maioria dos estudantes não sabe que a própria escola que frequentam prepara a merenda com base fundamentalmente em produtos orgânicos e livres de agrotóxicos.

Nesse sentido, insta analisar que, além de os produtos orgânicos serem uma forma sustentável de produção, são alimentos que trazem benefícios à saúde, qualidade de vida e preservam o meio ambiente.

Em meio a presente pesquisa, para o acolhimento das pretensões almejadas inicialmente, foi necessário proceder a algumas análises. Na análise responsável por verificar a percepção ambiental, a pesquisa demonstrou que os educandos do ensino fundamental 'possuem potenciais traços de percepção ambiental' e os dos ensinos médio e profissional 'possuem percepção ambiental', segundo a classificação do Modelo Vapercom.

Quanto à conduta/consumo, os alunos do ensino fundamental demonstraram possuir ' poucos traços de percepção ambiental'. Em contrapartida, os estudantes dos ensinos médio e profissional 'possuem traços de percepção ambiental'.

Em relação à $A C V$, os educandos do ensino fundamental e médio atenderam às questões propostas de modo a demonstrar que 'possuem potenciais traços de percepção ambiental', à medida que os do ensino profissional possuem percepção ambiental. A partir dos resultados apresentados nesse trabalho, resta 
evidenciado que a escola precisa melhorar suas ações referentes à informação dos alunos sobre os alimentos orgânicos utilizados no preparo da merenda escolar e, também, às ações relativas ao desenvolvimento sustentável.

Sugere-se, nesta oportunidade, que a instituição de ensino desenvolva projetos no sentido de investir na divulgação sobre a importância dos produtos orgânicos para a saúde, para o meio ambiente e para o desenvolvimento sustentável. Assim, recomenda-se o desenvolvimento de algumas ações que podem ser divulgadas por meio de veículos de comunicação, já disponíveis na escola, tais como:

- Divulgação de material informativo na conta do Facebook da escola;

- Criação de histórias em quadrinhos por meio de Gibi em espanhol já desenvolvido pela escola;

- Produção de um vídeo para ser divulgado por meio da televisão em rede da escola;

- Na Semana de Enfermagem, promovida pelo curso de enfermagem e realizada no mês de maio, apresentação de palestras sobre o tema.

- Desenvolvimento de um projeto direcionado aos pais dos educandos e à comunidade em geral.

A contribuição principal que essa pesquisa buscou alcançar, mesmo que não o tenha feito de maneira exaustiva, foi no sentido de demonstrar a percepção e o comportamento dos educandos em relação às questões ambientais, considerando a Análise do Ciclo de Vida do produto (ACV).

É notório, nesse contexto, que ainda é preciso intensificar os investimentos, tanto o governamental quanto o empresarial, às campanhas de divulgação acerca da importância dos benefícios gerados pelos produtos orgânicos para a saúde e para o meio ambiente, a fim de despertar, naquelas pessoas que até então não foram motivadas, a mudança de comportamento.

Ressalta-se, por fim, que esse estudo aponta para a necessidade de se fazer outras pesquisas a respeito das temáticas ora abordadas, com vistas ao melhor e mais abrangente entendimento das relações evidenciadas nesse trabalho. Sugere-se, dessa maneira, a aplicação do Modelo Vapercom por meio de diferentes amostras formadas por estudantes de outras instituições e de empresas de outros segmentos de mercado.

\section{REFERÊNCIAS}

BARBETTA, P. A., REIS M. M., BORNIA A.C. Estatística: para cursos de engenharia e informática. Atlas, 2004.

BARBIERI, J. C.; DA SILVA, D.. Desenvolvimento sustentável e educação ambiental: uma trajetória comum com muitos desafios. Revista de Administração Mackenzie, São Paulo, v.2, n.3, p.51-82, 2011.

BERTOLINI, G. R. F; BRANDALISE, L. T.; ROJO, C. A.; LEZANA, Á. G. R.. A viabilidade financeira no desenvolvimento de produtos ecológicos valorizados pelos consumidores. Revista de Gestão e Projetos, São Paulo, v.4, n.3, p.01-29, 2013.

BONILLA, S. H.; ALMEIDA, C. M. V. B; GIANNETTI, B. F.; HUISINGH, D.. The roles of cleaner production in the sustainable development of modern societies: an introduction to this special issue. Journal of Cleaner Production, v.18, p.1-5, 2010.

BRANDALISE, L. T.. A percepção do consumidor na análise do ciclo de vida do produto: um modelo de apoio à gestão empresarial. Cascavel: Edunioeste, 2008.

BRANDALISE, L. T.; BERTOLINI, G. R.; ROJO, C. A.; LEZANA, Á. G.; POSSAMAI, O.. A percepção e o comportamento ambiental dos universitários em relação ao grau de educação ambiental. Revista Gestão \& Produção, v.16, n.2, p.286-300, 2009.

BRASIL. Lei no $\mathbf{1 0 . 6 9 6}$ de 02 de julho de 2003. Dispõe sobre a repactuação e o alongamento de dívidas oriundas de operações de crédito rural, e dá outras providências. Diário Oficial da União, Brasília, 03 Jul 2003. 
BRASIL. Lei no 10.831, de 23 de dezembro de 2003. Dispõe sobre a agricultura orgânica e dá outras providências. Diário Oficial da União, Brasília, 24 dez 2009.

BRASIL. Lei no $\mathbf{1 1 . 3 2 6}$ de $\mathbf{2 4}$ de julho de 2006. Estabelece as diretrizes para a formulação da Política Nacional da Agricultura Familiar e Empreendimentos Familiares Rurais. Diário Oficial da União, Brasília, 25 Jul 2006.

BRASIL. Lei no 11.947, de 16 de junho de 2009. Dispõe sobre o atendimento da alimentação escolar e do programa dinheiro direto na escola aos alunos da educação básica. Diário Oficial da União, Brasília, 17 jun 2009.

BRASIL. Lei $\mathbf{n}^{\circ} \mathbf{9 . 7 9 5}$ de $\mathbf{2 7}$ de abril de 1999. Dispõe sobre a educação ambiental, institui a Política Nacional de Educação Ambiental e dá outras providências. Diário Oficial da União, Brasília,1999.

CAHILL, S.; MORLEY K.; POWELL, D. A.. Coverage of organic agriculture in north America newspapers - media: linking food safety, the environment, human health and organic agriculture, British Food Journal, v.112, n.7, p.710-722, 2010.

CAPRA, F.. Alfabetização ecológica: O desafio para a educação do Século 21. In.: Meio ambiente no Século 21. São Paulo, v.5, 2008.

COLTRO, A.. O comportamento do consumidor consciente como fonte de estímulos de mercado às ações institucionais socioambientais. Conselho Latino-Americano de Escolas de Administração, Montpellier France, 2006.

COSTA, D. V. D.; TEODÓSIO, A. D. S. D. S.. Sustainable development, consumption and citizenship: a study on the (dis) articulation of the communication of civil society organizations, government and companies. Revista de Administração Mackenzie, v.12, n.3, p.114-145, 2011.

CUNHA, M. B.. A educação ambiental no contexto escolar. In: ROESLER, M. R. B.. Por um meio ambiente ecologicamente equilibrado: pensamentos e diálogos. Cascavel: Edunioeste, 2010.

DENOBILE, T.. Modelo de gestão estratégica com foco no cliente para comercialização de produtos orgânicos. Dissertação (Mestrado em Engenharia Agrícola) Universidade Estadual de Campinas, Campinas, 2005.

\section{DIAS, G. F.. Atividades Interdisciplinares de Educação} Ambiental: Manual do Professor. Global/Gaia. São Paulo, 1994.

ELKINGTON, J.; HAILES J.; MAKOWER J.. The green consumer. New York, Penguin Books, 1990.

FERREIRA, M. C.. Gestão ambiental: práticas, condicionantes e evolução. Revista de Administração IMED, v.2, n.2, p.138150, 2012.

GIL, J. M.; GRACIA, A.; SANCHEZ, M.. Market segmentation and willingness to pay for organic products in Spain. International Food and Agribusiness Management Review, v.3, p.207-260, 2000.
GOMES, N. A. D. A. A.; CAMPOS, M. R. H.; MONEGO, E. T. Sanitary aspects of food preparation in public schools of Goiás, Brazil. Revista de Nutrição, v.25, n.4, p.473-485, 2012.

INSTITUTO AKATU. O que é consumo consciente?. Akatu, 2010.

JACOBI, P.. Educação ambiental, cidadania e sustentabilidade. Cadernos de pesquisa, v.118, n.3, p.189205, 2003.

JONES, P.; CLARKE-HILL, C.; SHEARS, P.; HILLIER, D.. Case study - Retailing organic foods. British Food Journal, v.103, n.5, p.358-365, 2001.

KOPEGINSKI, S. I. R.; SAKAMOTO, B. A. M.. Ética e educação ambiental. In: ROESLER, MARLI R. B.. Por um meio ambiente ecologicamente equilibrado: pensamentos e diálogos. Cascavel: Edunioeste, 2010.

KRISCHKE, P.; TOMIELLO, N.. O comportamento de compra dos consumidores de alimentos orgânicos: um estudo exploratório. Cadernos de pesquisa Interdisciplinar em Ciências Humanas, v.10, n.96, p.27-43, 2009.

MMA. Ministério do Meio Ambiente. Desenvolvimento Sustentável, educação ambiental e Agenda 21. Brasília, 2007.

OZCCELIK, A. O.; UÇAR, A.. Turkish academic staffs perception of organic foods. British Food Journal. v.110, n.9, p.948-960, 2008.

PAULISTA, G.; VARVAKIS G.; MONTIBELLER-FILHO, G.. Espaço emocional e indicadores de sustentabilidade. Ambiente \& Sociedade, v.11, n.1, 2008

PEARCE, D. W. Sustainable Development. Futures, v.20, n.6, p.598-605, 1988

POULSTON, J.; YAU, A.; YIU, K.. Profit or principles: why do restaurants serve organic food? International Journal of Hospitality Management, v.30, p.184-191, 2011.

RADMAN, M.. Consumer consumption and perception of organic products in Croatia. British food journal, v.107, n 4, p.263-273, 2005.

RASMUSSEN, J. E.. Transitioning to green: implementing a comprehensive environmental sustainability initiative on a university campus. Doctoral Dissertation, California State University, Long Beach, 2011.

RODRIGUES, R. R.; CARLOS, C. C.; MENDONÇA, P. S. M.; CORREA, S. R. A.. Atitudes e fatores que influenciam o consumo de produtos orgânicos no varejo. Revista Brasileira de Marketing, v.8, n.1, p.164-186, 2010.

ROHRICH, S. S.; CUNHA, J. C.. A proposição de uma taxonomia para análise da gestão ambiental no Brasil. Revista de Administração Contemporânea, v.8, n.4, p.81-97, 2004.

SACHS, I.. Desenvolvimento includente, sustentável, sustentado. Editora Garamond. Rio de Janeiro, 2004. 
SAHER, M.; LINDERMAN, M; ULLA-KAISA, K. H.. Attituddes towardes genetically modified and organic foods. Appetite. v.46, p.324-331, 2006.

SANTOS, A. P. L.; FERNANDES, D. S.. Análise do impacto ambiental gerados no ciclo de vida de um tecido de malha. Iberoamerican Journal of Industrial Engineering,

Florianópolis, v.4, n.7, p.1-17, 2012

SANTOS, T. C.; LEITE, A. P. R.; TACCONI, M.F.F.S.;

ALEXANDRE, M. L.. Movimento do consumo consciente: do cidadão consumidor ao consumidor cidadão. In Anais... Encontro de Administração Pública e Governança - EnAPG. Salvador, BA, Brasil, 2008.

SEED. Secretaria de Estado da Educação do Paraná. A agricultura familiar na merenda escolar ganha destaque nacional. 2013.

SERRANO, C. M. L.. Educação ambiental e consumerismo em unidades de ensino fundamental de Viçosa-MG.

Dissertação (Mestrado em Ciência Florestal) - Universidade Federal de Viçosa. Viçosa, 2003.

SILVA, M. E.; BALBINO, D. P; GÓMEZ C. P.. Consumo Sustentável na Base da Pirâmide: definindo papéis e obrigações para a efetivação do desenvolvimento sustentável. Revista de Gestão Social e Ambiental, São Paulo, v.5, n.2, p.18-33, 2011.

SLATER, D.. Cultura do consumo \& modernidade. São Paulo: Nobel, 2002.

SOARES, L. L.; VICENTE, E. F. R.. Divulgação das compras públicas de alimentos para a merenda escolar em municípios catarinenses. Gestão \& Regionalidade, São Caetano do Sul, v. 27, n. 80, p.30-44, 2011.

TERRAZZAN, P.; VALARINI, P. J.. Situação do mercado de produtos orgânicos e as formas de comercialização no Brasil. Informações Econômicas, São Paulo, v.39, n.11, 2009.

UNESCO - United Nations Educational Scientif and Cultural Organization - Organização das Nações Unidas para a Educação, Ciência e Cultura. Tendências de la educación. Paris: Unesco, 1997.

WCED. World Comissionn on Environment and Developmment. Report Our commom future. Genebra. 2014.

ZAKOWSKA-BIEMANS, S.. Polish consumer food choices and beliefs about organic food. British Food Journal. v.113, n.1, p.122-137, 2011. 